\title{
Study of Factors Influencing Cost Overruns: An Overview
}

\author{
Abhimanyu S. Rathi ${ }^{1}$, Pravin V.Khandve ${ }^{2}$ \\ ${ }^{1}$ Research Scholar, Department of Civil Engineering, PRMCEAM, Badnera- Amravati (MS) India \\ ${ }^{2}$ Assistant Professor and Member, Innovation and Entrepreneurship Development Center, PRMCEAM, Badnera - Amravati (MS) India
}

\begin{abstract}
Cost overruns have become issues of serious concern in construction industry. These overruns have detrimental effect on the national economy. Cost overruns have many reasons/factors which are not taken into consideration at the time of planning resulting into delays and cost increases. In the present study, we have studied literature and identified those factors influencing cost overruns. The primary findings emanating from the study revealed that empirical studies have identified a number of important factors which cause projects cost overruns. These factors have been categorized in different groups depending on their orientations. It is found that, understanding fundamentals of such factors is important role of construction manager for avoiding or minimizing cost overruns and better cost performances.
\end{abstract}

Keywords: Cost Overruns, National Economy, Cost Increases, Construction Manager, Cost Performances

\section{Introduction}

Construction has become an important player in the economy of many countries, especially developed countries. This industry contributes to the GDP and employment rate of many nations and for this reason it is considered vital for the economic development of any nation. Moreover, the construction activities have become a significant market due to the fact that this industry procures products and material from other businesses in other sectors. The more resources, engineering, labour, materials, equipment, capital, and market exchange are provided from within the national economy, the higher the factor of the extent of self reliance. The increasing complexity of infrastructure projects and the environment within which they are constructed place greater demand on construction managers to deliver projects on time, within the planned budget and with high quality.

Cost overruns reduce competitiveness of the economy. Services provided by infrastructure projects serve as input for other sectors of the economy. Cost overruns in construction projects lead to an increase in the capitaloutput-ratio for the entire economy. Infrastructure projects in India are infamous for delays and cost overruns. Indeed, very few projects get delivered in time and on cost. The cost overruns have become hallmark of infrastructure projects in India. In an attempt to shed some light on how each construction project party perceives the relative importance of these cost overrun factors. This study is carried out with an objective to understand major and minor factors leading to cost overruns which helps in improving the performance of the industry and benefit the infrastructure industry. Cost overruns reduce competitiveness of the economy. Services provided by infrastructure projects serve as input for other sectors of the economy. Cost overruns in construction projects lead to an increase in the capital-output-ratio for the entire economy. Infrastructure projects in India are infamous for delays and cost overruns.

\section{Objective}

The problem of cost overrun, especially in the construction industry, is a worldwide phenomenon. A project in the construction is considered successful if it is completed on time, within budget and to specification or quality standard. However, in the recent past it is seen that most projects get delayed due to certain factors leading to cost and time overruns. Thus, this study is carried out with an view to understand such factors influencing cost increases and suggesting some remedial measures by a thorough analysis.

\section{Literature Review}

Various literatures are studied to get an overview of construction cost overruns factors and minimizing their effects on the construction project in the most economical way and to know various research studies related to efficient and economic ways of construction.

K.Deeppa and I.Krishnamurthy analyzed the time and cost overruns in Infrastructure projects in India and explained the typical causes of project cost and time overruns and provided some useful tips and techniques for managing and reducing costs. They derived Principal Component analysis and Relative Importance index (RII). The analysis of response data revealed that there were variables that significantly contributed to the cost and time overruns and had a chance of recurring in future projects. This paper discusses about time and cost overruns in a conceptual way followed by the study of previous researches on measuring time and cost overruns. Secondly the paper describes the results of empirical studies carried out in Indian context that investigates the occurrence of time and cost overruns in the infrastructure industry. The study is carried out with an objective to find out measure factors leading to cost and time overruns which are indicated for improving the performance of the industry and which would the benefit the infrastructure industry.

Susana Gomez Arcila in paper Avoiding Cost Overruns in Construction Projects (August 2012), carried out a literature review which helped in finding the main causes of cost overruns on construction projects. This paper was an attempt to identify factors that can help avoid cost overruns 


\section{International Journal of Science and Research (IJSR) \\ ISSN (Online): 2319-7064 \\ Index Copernicus Value (2013): 6.14 | Impact Factor (2014): 5.611}

on construction projects. This paper aimed to identify some critical success factors that can help to improve cost performance in construction projects in the UK. Firstly, the main causes of cost overruns in construction projects in the United Kingdom are understood. This research confirmed the fact that there are certain Critical Success Factors that can help avoid or prevent cost overruns on construction projects, in the UK. However, the use of a multi-case study strategy in this research did not allow finding a unique list of Critical Success Factors that can prevent cost overruns. Another suggestion for further research is to carry out the same multi case-study strategy used in this research, but with projects from the public sector. a multi-case study in the public sector can be done to compare the results with this research. In that case, some different or similar CSFs can be found with this comparison. This research can be useful to understand differences between the public and private sector construction, in the United Kingdom.

According to A. M. El-Kholy (2015), the accuracy of early cost estimates in engineering and construction projects is extremely important to both owners and project teams. For this study, the author used and presented two models for predicting cost overrun percentage in construction projects. The first model is based on regression analysis. 44 factors that impact cost performance in construction projects gathered from literature. Eleven most significant factors that lead to cost overrun are found to be independent variables of the proposed model. Data was collected for occurrence of the previous factors on yes/no basis and the corresponding cost overrun percentage (dependent variable) for 30 construction projects and was divided into two sets. The results revealed that there is a strong linear relationship between cost overrun percentage and the previous 11 causes that significantly affect cost overrun of projects. The second model is a case based reasoning (CBR) model. CBR method can be an effective means of utilizing knowledge gained from past experience to estimate percentage cost overrun in construction works. The study revealed that validation of the two models using projects of set revealed that regression model has prediction capabilities higher than that of CBR model. It provided an approach for industry practitioners to predict cost overrun percentage for construction projects. On the other hand, it provides researchers with a methodology to build regression and case based reasoning models for cost overrun percentage prediction. Computer implementation for case based reasoning model is suggested for future research, for easily implementation.

Chintan Hitesh Patel, Himanshu Chaturvedi, Megha R.Rao, Priyanka Katta and K.N. Narasimha Prasad (June 2015),conducted an analysis of cost and time overruns in construction projects, for identifying the possible reasons for the overruns and verifying through a questionnaire survey with government engineers to identify the critical reasons for cost and time overruns. Statistical analysis used in the study involves univariate analysis wherein rankings are tested for correlation using Spearman's rank correlation technique and one tailed tests. From this study it was concluded that the factors affecting cost and time overruns aren't the same, but are interdependent. It also concluded that the cost overruns are due to variations in the quantities estimated and actually executed. The study revealed that cost overruns in
Government construction projects is a norm which continues despite introduction of new bidding models, e-tendering techniques and third party inspections. It suggested that on identification of a project, team of experts either from within the department, private consultants or in combination is to be constituted. This committee should to go through project in a scientific manner and assure responsibility for its proper planning and execution.

\section{Factors Influencing Cost Overruns:}

Based on the literature and related work, following are some factors influencing cost overruns in construction projects,

\subsection{Design Related}

Design related factors leading to cost overruns are critical in construction projects. Often these factors lead to cost increases and affect the project performance. These factors include inaccurate estimation at the time of preparing, changes in design at the time of construction, incomplete design at the time of tender. Sometimes the time allowed for the preparation of an estimate is less comparing to the size and span of project which often leads to mistake in estimating.

\subsection{Material Related}

Material related factors are commonly seen in any construction project. Often it is seen that the cost of materials used for construction are fluctuating. If the schedule of certain project is longer than one year or two it becomes necessary for the management team to take the escalation of prices into consideration. Similarly, delay in supply of raw materials \& equipment by competent authority may lead to cost increases.

\subsection{Site Related}

Site related factors majorly include Rework of bad quality performance. Often it is seen that project participants either the contractor or owner, for their personal benefits compromise with the quality of work. However, in most of the cases such works are to be carried out again as they are not matching the substantial standards. In working it is usually seen that Site layout is major issue leading to delay in start of construction. Often land acquisition for construction of roads/bridges is a serious problem causing delays in start of work. Unknown Geological Conditions/ Sub Soil Conditions are one of the main factors leading to cost increases. The assumed soil bearing capacity by the consulting agency may vary with geological conditions leading to changes in design affecting cost. Inappropriate choice of site refers to the improper location and approach road to the work place leading to increase in transportation costs.

\subsection{Finance Related}

Poor financial condition of owner may lead to delays in construction leading to uncompleted work or partial fulfillment of work. Cash Problem during construction may 


\section{International Journal of Science and Research (IJSR) \\ ISSN (Online): 2319-7064 \\ Index Copernicus Value (2013): 6.14 | Impact Factor (2014): 5.611}

lead to delayed payments which may force the project participants to withdraw or upheld project leading to overruns. Poor financial control over site leads to wastage of material and rework of items not carried out to the required standards which in turn results into delays and cost overruns.

\subsection{Owner Related}

Change in Scope of Project is one of the reasons of cost increase. Decisions regarding different aspects of project are expected from owner on schedule. However delay is making decisions may affect the contractor's interest leading to cost overruns. Delay in preliminary handing over of project place by the owner leads to cost overruns for the contractor and project. Conflict among project participants for any issues may lead to delays and affect cost.

\subsection{Contractor Related}

When it comes to cost overruns in construction projects, contractor related factors are severe and have very severe effect on project. Bad allocation of workers by the contractor may lead to improper finishing of work which may lead to rework affecting cost. Mistakes during construction and lack of experience of technical expertise may lead to reworking and affect cost substantially. Abandoning of work midway by the contractor may result in huge losses to the project leading to cost overruns.

\subsection{Miscellaneous Factors}

Execution of non-tendered items, unavailability of electricity and water, bad weather conditions and lack of coordination of local neighbours are some of the miscellaneous factors which may lead to delay in completion of work and subsequently lead to cost overruns.

\section{Results and Conclusion}

In this rapidly increasing construction sector, cost of the project is very much important from the feasibility point of view. Now-a-days, due to labor problems, market slowdowns and changing business environment certain parameters are necessary to be considered for success of project Thus, it is essential to understand it's fundamentals towards success of project.

In this paper, we have studied different literatures related to cost overruns and its causes. We studied the various factors which shall be controlled to avoid the effect of cost overruns and minimize the extra costs.

1. Inaccurate estimates and design changes at the time of construction may directly affect the cost found initially.

2. It is necessary that the project management team has a good forecasting technique to know the future business environment. This will help the owner or agency to take decision regarding procurement of materials.

3. It shall be taken into notification that acquisition of land, NOCs from the government agencies shall be taken prior to the commencement of project as it will help to avoid delays during execution.
4. There shall not be change in the scope of project by any of the stakeholders and conflict among these participants to avoid and minimize delays in construction.

5. The contractor shall have good relations with the neighbours at work place to have good coordination from them to successfully complete project. Also minor issues regarding the availability of water, weather conditions shall be analyzed before commencement of project.

Thus, it is important to study these cost overruns factors and to avoid it for maximum benefits and returns from construction project.

\section{References}

[1] M. El-Kholy, "Predicting Cost Overrun in Construction Projects," Civil Engineering Dept., Faculty of Engineering, Beni-Suef University, Beni-Suef, Egypt, International Journal of Construction Engineering and Management 2015, 4(4): 95-105.

[2] Chintan Hitesh Patel, Himanshu Chaturvedi, Megha R.Rao, Priyanka Katta and K.N. Narasimha Prasad, “An Analysis of Cost \& Time Overruns in Construction Projects", NICMAR- Journal of Construction Management, Vol. XXX, No. 2, April-June 2015.

[3] Overrun Nida Azhar, Rizwan Farooqui, Syed M. Ahmed," Construction Factors In Construction Industry of Pakistan", First International Conference on Construction In Developing Countries, Karachi, Pakistan, August 2008.

[4] Ruth Apolot, Henry Alinaitwe and Dan Tindiwensi, “ An Investigation into the causes of Delay and Cost Overrun in Uganda's Public Sector Construction Projects", Second International Conference on Advances in Engineering and Technology.

[5] Eradius E. Rwakarehe and David A. Mfinanga," Effect of Inadequate Design on Cost and Time Overrun of Road Construction Projects in Tanzania", KICEM Journal of Construction Engineering \& Project Management, September 2013.

[6] Thillai A. Rajan, Govind Gopinath and Monalisa Behera, "PPPs and Project Overruns: Evidence from Road Projects in India", American Society of Civil Engineers 2013. 